\title{
Akciğer Solunum Seslerinin Spektral Öznitelikler ile Sınıflandırılması
}

\author{
Sezer ULUKAYA ${ }^{1,2}$, Görkem SERBES ${ }^{* 3}$, İpek ŞEN ${ }^{4}$, Yasemin P. KAHYA ${ }^{1}$
}

${ }^{1}$ Boğaziçi Üniversitesi, Mühendislik Fakültesi, Elektrik-Elektronik Mühendisliği Bölümü, 34342, İstanbul 2Trakya Üniversitesi, Mühendislik Fakültesi, Elektrik-Elektronik Mühendisliği Bölümü, 22030, Edirne ${ }^{3}$ Yıldız Teknik Üniversitesi, Elektrik-Elektronik Fakültesi, Biyomedikal Mühendisliği Bölümü, 34220, İstanbul

${ }^{4}$ Beykent Üniversitesi, Mühendislik-Mimarlık Fakültesi, Elektrik-Elektronik Mühendisliği Bölümü, 34398, İstanbul

(Alınış / Received: 27.01.2017, Kabul / Accepted: 17.08.2017, Online Yayınlanma / Published Online: 01.11.2017)

\section{Anahtar Kelimeler}

Akciğer solunum sesleri,

Çıtırtı,

Üfürüm,

Mel frekans kepstral katsayıları,

Güç spektrum yoğunluğu,

Algısal doğrusal öngörü katsayıları
Özet: $\mathrm{Bu}$ çalışmada güç spektrum yoğunluğu, mel frekans kepstral katsayıları (MFKK) ve algısal doğrusal öngörü (ADÖ) yöntemleri; çıtırtı, üfürüm ve normal akciğer solunum seslerini ayrıştırmak amacıyla kullanılan öznitelik çıkarıcılar olarak görevlendirilmiștir. Ham özniteliklerden sekiz alt öznitelik kümesi (enerji, entropi, en küçülten, en büyülten, ortalama, standart sapma, eğrilik ve basıklık) çıkarılarak $k$-en yakın komşu ve destek vektör makineleri sınıflandırıcılarına birini dışarıda bırak şeması kullanılarak beslenmiştir. Önerilen algısal doğrusal öngörü katsayıları yöntemi güç spektrum yoğunluğundan daha iyi performans sergilerken mel frekans kepstral katsayıları ile başa baş performans göstermiştir. ADÖ yönteminin üç gruplu sınıflandırma performansı var olan literatürle karşılaştırılmıştır. Çıtırtı, üfürüm ve normal sınıfları (\% 94, \% 95.5, \% 95.5 sırasıyla) için en iyi sonuçlara ADÖ tarafından ulaşılmıştır. Diğer taraftan tüm sınıf doğruluklarının en iyi ortalama sonucuna \% 91.3 ile MFKK tarafından ulaşılmıştır. MFKK ve ADÖ yöntemlerinin sınıflandırma doğruluğunun model derecesine oldukça bağlı olduğu gözlemlenmiștir.

\section{Classification of Respiratory Sounds Using Spectral Features}

\section{Keywords}

Respiratory sounds,

Crackle,

Wheeze,

Mel frequency cepstral coefficients,

Power spectral density,

Perceptual linear prediction coefficients

\begin{abstract}
In this study, power spectral density (PSD), mel frequency cepstral coefficients (MFCC) and perceptual linear prediction (PLP) methods are employed as feature extraction methods for discriminating crackle, wheeze and normal respiratory sounds. Eight sub-feature subsets (energy, entropy, minimum, maximum, mean, standard deviation, skewness and kurtosis) that are extracted from raw features are fed into $k$-nearest neighbour and support vector machine classifiers in a leave-oneout cross validation scheme. It is seen that proposed method PLP shows better performance than PSD and shows break-even performance with MFCC. Three class classification performance of PLP method is compared with existing literature. Best result for crackle, wheeze and normal classes ( $94 \%, 95.5 \%, 95.5 \%$ respectively) is reached by PLP. On the other hand, the best average accuracy is represented by MFCC with a $91.3 \%$ value. It has been observed that the classification accuracy of MFCC and PLP is highly dependent on the model order.
\end{abstract}

\section{Giriş}

Analog stetoskop $120 \mathrm{~Hz}$. üzerindeki frekansları sönümlendirmekte ve bu frekans aralığındaki bilginin kaybolmasına sebep olmaktadır [1]. Ayrıca, stetoskop vasitasıla dinlenilen sesler kayit altına alınamamaktadır. Bu sebeplerden dolayı, günümüzde yerini disiplinler arası çalışmaların da katkısıyla elektronik stetoskoba [2] bırakmaya başlamıştır. Akciğer solunum sesleri normal (vesicular) ve ek-ses (adventitious) olmak üzere ikiye ayrılırlar. Normal sesler sağlıklı insanlarda gögüs kafesinden dinlenilen 

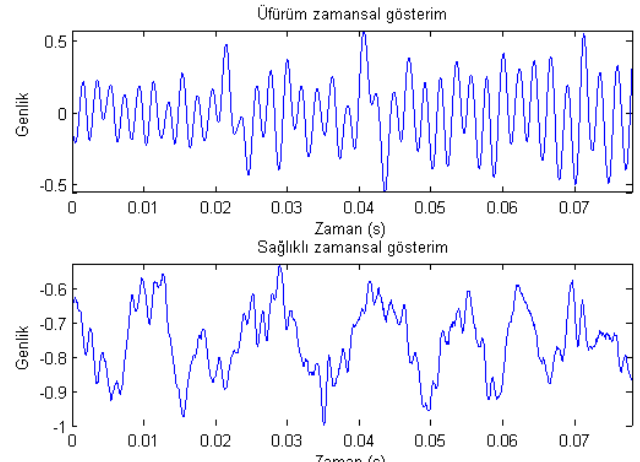

Catiritı zamansal gösterim

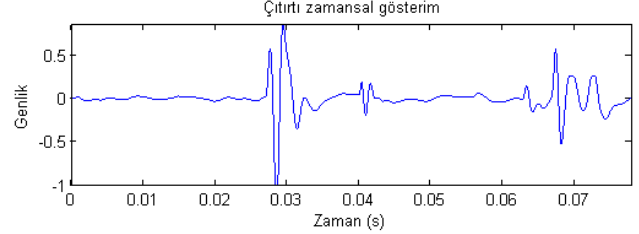

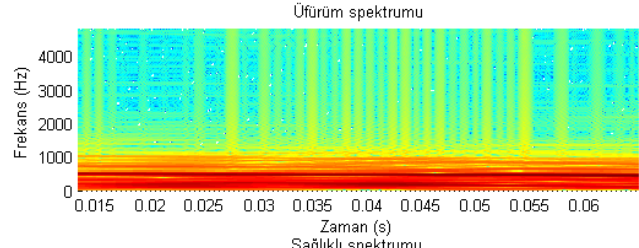

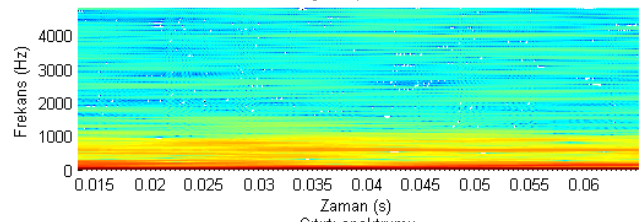
çttritı spektrumu

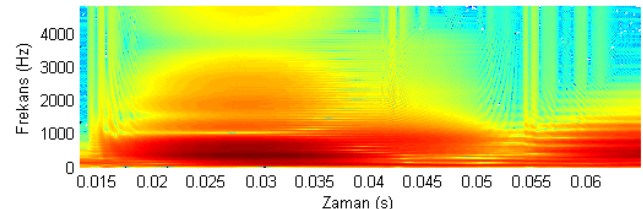

Şekil 1. Birer adet üfürüm (en üst), sağlıklı (orta) ve çıtırtı (en alt) işaretinin zaman (sol) ve frekans (sağ) alanı gösterimi

ve akciğerdeki hava akışı ile eş zamanlı duyulan seslerdir. Sağlıklı insanlarda normal sesler 200-600 $\mathrm{Hz}$ frekans aralığında baskındır [3]. Ek-sesler ise normal seslerin üzerine eklenen ve çeşitli akciğer hastalıklarının teşhisi için hayati bilgi taşıyan dalga çeşitleridir. Ek-sesler sürekli ve ayrık olmak üzere iki gruba ayrılırlar. Sürekli seslerin en belirgin örneği üfürüm (wheeze) iken ayrık seslerin en belirgin örneği ise çıtırtı (crackle) olarak adlandırılır. Çıtırtı sesleri, zaman alanında ani ve keskin enerji patlamalarından oluşan, genellikle 20 ms'den az süren, ve 200-2000 Hz. frekans aralığında değişen ekseslerdir [4]. Nefes alış-verişi esnasında meydana gelen çıtırtıların sayısı hastalığın önem derecesi, zamanlaması, süresi ve tipi ise hastalığın çeşidi hakkında bilgi vermektedir [5]. Çıtırtılar kaba ve ince olmak üzere iki çeşittir, kaba çıtırtılar bronşektazi hastalarında gözlemlenirken, ince çıtırtılar ise interstisyal fibrozis ve zatürre hastalarında gözlemlenir [6]. Müzikal dalga yapısına sahip olan üfürümler ise $100 \mathrm{~Hz}$.'ten büyük frekanslarda, frekans düzleminde ayrık tepeler şeklinde 80-250 ms süren yüksek enerjili sinüzoidal sinyallerdir [7]. Kullandığımız veritabanında yer alan birer adet üfürüm, sağlıklı ve çıtırtı işaretinin zaman ve frekans alanı gösterimi örnek olarak Şekil 1'de verilmiştir.

Üfürümlerin varlığı genellikle astım ve kronik obstrüktif akciğer hastalığı (KOAH) göstergesidir. Üfürümlerin baskın frekans değerleri ve süreleri akciğer içindeki hava yollarının tıkanıklık derecesi ile doğru orantılıdır [7]. Hem zamanda hem de frekans bölgesinde normal, çıtırtı ve üfürüm sinyalleri arasında gözle görünür bir örtüşme olması problemin çözümünü zorlaştırmakla birlikte, bu seslerin hastalıklı-sağlıklı ayrımında çok önemli olmaları bizi bu sesleri en yüksek başarımla ayırmaya çalışan yöntemleri aramaya itmiştir. Literatürde üç grup sınıflandırma problemi için güç spektrum yoğunluğu $[8,11]$ ve Mel frekans kepstral katsayıları (MFKK) $[9,10]$ yöntemlerini öneren birkaç çalışmaya rastlanılmıştır. [8]'de, 96 öznenin yarısı eğitim diğer yarısı ise test amaçlı kullanılmıştır. Bu çalışmada elde edilen güç spektrum yoğunluğu öznitelikleri, genetik algoritma ile seçilmiş ve ilgili öznitelikler çok katmanlı algılayıcı yapay sinir ağları (Multilayer perceptron neural network) ile sinıflandırarak \% 91.7 doğruluk oranına ulaşmıştır. [9]'da veri kümesinden MFKK öz-nitelikleri çıkarılmış ve saklı Markov model (hidden Markov model) ile modellenerek en-büyük olabilirlik (maximum likelihood) tabanlı bir sınıflandırıcı yardımıyla \% 83 doğruluk oranına ulaşılmıştır. MFKK özniteliği kullanılan bir başka çalışmada [10], Gauss karıșım modelleri (Gaussian mixture model) tabanl sınıflandırıcı kullanılarak eğitimde \% 98.75, testte ise \% 52.5 doğruluk elde edilmiştir. Güç spektrum yoğunluğu (Power spectral density) öznitelikleri kullanılarak çıkarılan verinin doğrudan çok katmanlı algılayıcı yapay sinir ağları ile sınıflandırıldığı çalışmada [11] ise \% 88.7 doğruluk oranına ulaşılmıştır. Önerilen çalışmada ise akciğer solunum seslerini ayırt edebilmek amacıyla; güç spektrum yoğunluğu ve MFKK gibi Fourier dönüșümü tabanlı, klasik yöntemlere ek olarak, ilk defa kișiden bağımsız konuşma tanıma amacıyla önerilmiş [12], algısal doğrusal öngörü (Perceptual linear prediction) öznitelikleri kullanılmıștır. Önerilen yöntemin başarısı literatürdeki diğer yöntemlerin referans veri tabanımız üzerindeki başarı oranları ile karşılaştırılmıştır. Solunum sesleri alanında kullanılan veriler genellikle farklı özelliklerdeki cihazlardan ve farklı akciğer bölgelerinden alınmaktadır. Ayrıca kullanılan cihazların örnekleme frekansları da aynı olmamaktadır. Bu sebeplerden dolayı literatürde karşılaştırmalı sonuçlara nadir olarak rastlanmaktadır. $\mathrm{Bu}$ çalışmada, aynı veri kümesi ve aynı sınıflandırıcılar kullanılarak farklı öznitelik çlkarma yöntemleri ile literatürle karşılaştırmalı bir çalışma yapılmıştır. Ayrıca, elde edilen özniteliklerin enerji (energy), entropi (entropy), standart sapma (standard deviation), 
ortalama (mean), en küçük (minimum), en büyük (maximum), eğrilik (skewness) ve basıklık (kurtosis) gibi istatistiksel alt kümeleri kullanılarak yapılan sınıflandırma sonucunda daha az öznitelikle, en yüksek başarıma ulaşılmaya çalışılmıştır.

Çalışmada sırasıyla 2. bölümde kullanılan yöntemler, 3. bölümde deneysel sonuçlar, 4 . bölümde ise vargılar ve tartışmaya yer verilmiştir.

\section{Materyal ve Metot}

$\mathrm{Bu}$ bölümde önce kullanılan veri tabanı tanıtılmış, daha sonra ise kullanılan öznitelik çıkarma yöntemleri ve deneysel kurulum hakkında bilgi verilmiştir.

\subsection{Veri toplama}

Bu çalışmada, Boğaziçi Üniversitesi Solunum Sesleri Laboratuvarı 'nda tasarlanan 14 kanallı veri toplama sistemi [13] ile kayıt edilen veri tabanı kullanılmıştır. Solunum sesi kaydı yapan mikrofonların gögüs kafesi üzerindeki konumları Şekil 2'de verilmiştir. Her bir veri alımı 15 saniye sürmüş ve örnekleme oranı saniyede 9600 örneğe karşılık gelmiştir. Kayıtlar yapılmadan önce her kişiden bilgilendirilmiş olur onayı alınmıştır. Ayrık ve sürekli hastalık ses örnekleri İstanbul Yedikule Gögüs Hastalıkları ve Göğüs Cerrahisi Eğitim ve Araștırma Hastanesi'nde tedavi altında olan hastalardan alınmıștır. Veri tabanı on dördü erkek, altısı kadın olmak üzere yirmi kişiden oluşmaktadır.

Normal sesler ise daha önce herhangi bir akciğer rahatsızlığı geçirmemiş on kişiden alınmıştır. Çıtırtı, üfürüm ve normal sınıfları için sınıf başına 200 bölüt (segment) ses kullanılmıştır, toplamda ise 600 bölüt ses örneği kullanılmıştır. Elde edilen ses örnekleri uzman hekim tarafından hem dinlenilerek hem de görsel olarak doğrulanmış ve sınıfına göre çıtırtı, üfürüm veya normal olarak etiketlenmiștir. Bölütlerin uzunlukları literatürde ilgili sınıfa ait en kısa zaman dilimiyle uyumlu olacak şekilde değișkendir, bölütlerdeki çıtırtı sayısı birden fazla olabilmektedir. Bölütlerde, önerilen sistemin gerçekliğini arttırmak adına, zaman-frekans özelliklerine göre tek ve çok sesli üfürümler kullanılmıștır.

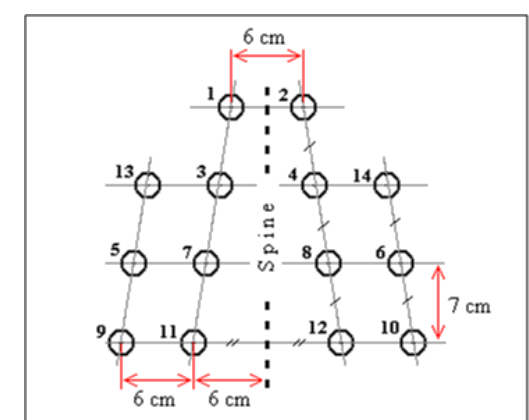

Şekil 2. Solunum sesi kaydı yapan mikrofonların gögüs kafesi üzerindeki konumları. Şekil, [13] den alınmıştır.

\subsection{Güç spektrum yoğunluğu}

Solunum sesi penceresi bir zaman serisi $x(k)$ olarak düşünülürse, güç spektrum yoğunluğu aşağıdaki şekilde hesaplanır;

$$
P(f)=\frac{1}{K}\left|\sum_{k=0}^{K-1}\left(x_{i}(\mathrm{k}) \mathrm{w}(\mathrm{k})\right) \mathrm{e}^{-\mathrm{j} 2 \pi \mathrm{fk}}\right|^{2}=\frac{1}{K}|X(f)|^{2}
$$

$i=0, \ldots, M-1$ olmak üzere, $X(f), x(k)$ nın Fourier dönüşümüne karşılık gelmektedir. Welch yöntemi güç spektrum yoğunluğunun $w(k)$ pencereleri ile çarpılmasına ve veri bölütlerinin örtüşmesine izin verdiğinden dolayı kullanım kolaylığı sağlamaktadır [14] ve literatürdeki yöntemlerce de tercih edilmiștir $[8,11]$. Welch yöntemi her bir pencerelenmiş bölütün güç spektrum yoğunluklarının ortalamasına denk gelmektedir ve ortalaması alınmış güç spektrum yoğunluğu olarak adlandırılabilir. Solunum ses bölütleri 256 lık Hamming pencereleri (Hamming window) ile \% 50 örtüşme (overlap) olacak şekilde çarpılmış ve daha sonra 256 noktalı hızlı Fourier dönüşümü [8] alınmıştır. Elde edilen 129 noktalı spektrum katsayılarının logaritması (log spectrum) alınmış ve enerji, entropi, standart sapma, ortalama, en küçük, en büyük, eğrilik ve basıklık alt kümeleri çıkarılıp sınıflandırıcılara verilmiştir.

\subsection{Mel frekans kepstral katsayıları}

MFKK otomatik konuşma tanıma için önerilmiş daha sonra akciğer akustiğine de uygulanmıștır. MFKK yöntemi genel olarak insanın işitme sistemini modelleyip doğrusal olmayan mel ölçeğine (Mel scale) göre spektral olarak benzetmeye çalışmaktadır. Denklem 1 de gösterildiği gibi solunum ses bölütü frekans bölgesine geçirilir, daha sonra her bir bölütün genlik spektrumu (amplitude spectrum) bulunur. Mel pencereleri düşük frekanslarda sık, yüksek frekanslarda seyrek dağılım gösteren üçgen süzgeçlerden (triangular filters) oluşmaktadır ve $f(m e l)=1125 * \ln (1+f / 700)$ ile mel frekans ölçeğine çevrilirler. Süzgeç öbeği (Filter group), güç spektrum yoğunluğuna uygulandıktan sonra her bir süzgecin enerjisi hesaplanır ve teorik olarak bu mel süzgecinin frekans tepkisi yani art arda bant geçiren süzgeçlerin frekans tepkisini vermektedir. Son olarak Ayrık Kosinüs Dönüşümü (Discrete Cosine Transform) uygulanarak MFKK bulunur;

$$
\operatorname{MFKK}=\sum_{k=1}^{N} \mathrm{P}(\mathrm{k}) \cos \left(\mathrm{n}\left(\mathrm{k}-\frac{1}{2}\right) \frac{\pi}{\mathrm{K}}\right)
$$

öyle ki $n \geq 0$ ve $n<K, K$ ise toplam katsayıların sayısıdır, $P(k)$ ise süzgeçlerin çıktısıdır.

\subsection{Algısal doğrusal öngörü öznitelikleri}

Bu öznitelik çıkarma yöntemi daha önce sağlıklı ve hasta insanları 15 saniyelik kanalları ayırmadan ham öznitelikleri kullanarak ikili sınıflandırma amacıyla önerilmişti [15]. $\mathrm{Bu}$ çalışmada ise geçmişteki 
çalışmadan farklı olarak hastalıklara özel anormalliklerin (çıtırtı ve üfürüm vb.) olduğu bölütler üzerinden çlkarılan özniteliklerin çeşitli alt kümelerinin üçlü sınıflandırma (normal, çıtırtı ve üfürüm sınıfları) üzerindeki başarımı başka yöntemlerle (Mel frekans kepstral katsayıları ve güç spektrum yoğunluğu) de karşılaștırılarak incelenmiştir. Bu öznitelik çlkarma yöntemi ilk olarak kişiden bağımsız otomatik konuşma tanıma amacıyla önerilmiştir [12]. Bu çalışmada, ADÖ yönteminin kişiden bağımsız hastalıkların ayrımsayıcı (discriminative) özelliklerini ortaya çıkarmasını ve başarımı iyileştirmesini beklemekteyiz. Bu yöntem, spektrumu kişiye özel (subject specific) özellikleri en küçülterek bükmeyi (warping) ve en önemli ayrımsayıcı öznitelikleri bulmayı amaçlamaktadır.

Solunum sesi penceresi zaman serisi $x(k)$ 'nın Hamming penceresi ile \% 50 örtüşme olacak şekilde yumuşatılması sonrası 256 lık hızlı Fourier dönüşümü Denklem 1 deki gibi hesaplanır. Her bir bölütün genlik spektrumu bulunur, $\tau(f)=$ $\left.6 \ln \left(w / 1200 \pi+(w / 1200 \pi)^{2}+1\right)^{0.5}\right) \quad$ ile Bark ölçeğine (Bark scale) dönüştürülen frekanslar, hızlı Fourier dönüşümü sonucu elde edilen frekans kutuları (frequency bins) kritik frekans gruplaması ile Bark kutucuklarında birleştirilir [12]. Bu işlem sonucunda seyreltilen frekans kutucuklarında farklı sınıflara ait tepkilerin farklı yoğunlukta ve sayıda olması beklenir. İnsan işitmesine benzetebilmek amacıyla sırasıyla eşit ses şiddeti önvurgulaması (pre-emphasis) ve kübik kök genlik sıkıştırması uygulanır [12]. Ters hızlı Fourier dönüşümü alınan sinyal $n$. dereceden tüm kutup modeli (all pole) ile Yule-Walker denklemleri çözdürülerek özbağlanımlı (autoregressive) katsayllara ulaşılır;

$$
\mathrm{x}(\mathrm{n})=\sum_{k=0}^{N} \mathrm{a}_{\mathrm{k}} \mathrm{y}(\mathrm{n}-\mathrm{k})
$$

öyle ki N model derecesi, $y(n-k)$ geçmiş çıkışlar, $x(n)$ ise giriştir.

\subsection{Deneysel kurulum}

Güç spektrum yoğunluğunu kullanan yöntemler ya ham öznitelikleri [11] (129'luk vektör) ya da öznitelik seçimi yaparak [8] elde ettikleri bilgiyi yapay sinir ağlarına sınıflandırma amacıyla vermişlerdir. $\mathrm{Bu}$ çalışmada güç spektrum yoğunluğunu Welch yöntemi ile 256 noktalı hızlı Fourier dönüşümü kullanarak hesapladık. Öncesinde \%50 örtüşmeli 256 elemanlı Hamming pencereleri seçildi ki bu hem literatür ile uyumlu [8,11] hem de çıtırtıların $10 \mathrm{~ms}$. civarında sürdüğü düşünülürse bir pencere içinde en az bir çıtırtı olmasını sağlamaya dönüktür.

MFKK ve ADÖ için de yukarıda anlatılan benzer ön işleme süreci izlenmiş olup kullanılan yöntemin derecesi literatürde önerilen derecelere (Ref. [6] için 6., [9] için 5., [10] için 13. derece) göre 3 den 13 e kadar deneysel olarak doğrulanarak seçilmiştir.
Sınıflandırıcı olarak destek vektör makineleri ve $k$-en yakın komşu sınıflandırıcıları kullanılmıştır. Destek vektör makineleri, doğrusal ve radyal temelli fonksiyon çekirdekleri için, çeşitli $C$ ve gamma $(g)$ değerleri denenerek en iyilenmiştir. $k$-en yakın komşu sınıflandırıcısında ise komşuluk $(k)$ değerleri 1'den 10'a kadar denenmiştir. Sonuçların nesnel olabilmesi amacıyla birini dışarıda bırak çapraz geçerleme (Leave-one-out cross validation) şeması kullanılmıştır, sınıf bazlı doğruluk değerlerinin yanı sıra tüm sınıfların doğruluklarının ortalaması da bulunmuştur.

\section{Bulgular}

Tablo 1 de çıtırtı, üfürüm ve normal sesler için güç spektrum yoğunluğu, mel frekans kepstral katsaylları ve algısal doğrusal öngörü katsayıları için $k$-en yakın komşu ve destek vektör makineleri doğruluk sonuçları verilmiştir. Ayrıca, üç sınıfın doğruluk sonuçları üzerinden ortalama doğruluk da hesaplanmıştır. Bulunan sonuçların sınıflandırıcılar arası istatistiki testleri eşleştirilmiş iki grup t-test (paired samples t-test) ile yapılmış olup, p-değerleri (en büyüğü 0.0021 olmak üzere) $\mathrm{p}<0.05$ koşulunu sağlayarak anlamlı çıkmıştır.

Tablo 1 deki sonuçlara göre ADÖ ve MFKK bariz bir şekilde güç spektrum yoğunluğundan daha yüksek başarıma ulaşmıștır. Bunun sebebi, MFKK ve ADÖ nün düşük frekanslarda zaman çözünürlüğü iyi olmayan güç spektrum yoğunluğundan daha iyi frekans çözünürlüğüne sahip olması ve sabit zamanfrekans çözünürlüğü kullanmasıdır. ADÖ ve MFKK kendi aralarında ise birbirine çok benzer yöntemler olduklarından üç alt öznitelik grubunda (enerji, standart sapma ve en büyülten) ADÖ, diğerlerinde ise MFKK en yüksek ortalama başarıma ulaşmıştır.

ADÖ ve MFKK bant geçiren süzgeçleri sırasıyla oval (çan) ve üçgen tipte olduğundan bazı durumlarda üçgen bazı durumlarda da oval tipteki süzgeçler daha ayrımsayıcı frekans tepkilerini ortaya çıkarmışlardır. Ortalama ve eğrilik alt grup sonuçları ise diğerlerinden daha düşük çıtığından tabloya konulmamıştır.

MFKK ve ADÖ sonuçları incelendiğinde en iyi sonuçların en küçülten, enerji ve en büyülten alt grupları ile elde edildiği bulunmuștur. Bunun sebebi, bant geçiren süzgeçlerin enerji dağılımlarının en büyük ve en küçük değerlerinin ayırıcı özellikleri ön plana çıkarabilmesidir. Örneğin üfürüm belirli frekanslarda yoğun enerjiye sahiptir ve o bant yeterince iyi lokalize edilebilirse ayırıcı özelliği ön plana çıkacaktır, aynı şekilde normal seslerin enerjisi çıtırtıya göre yüksek frekanslarda düşük kalmaktadır [6].

$k$-en yakın komşu sınıflandırıcısı için en iyi sonuçlar 3. komşu ile alınmıştır, $k$-en yakın komşu sınıflandırıcısı DVM sınıflandırıcısına göre ortalama 
doğruluk değerlerinde birkaç senaryoda daha iyi sonuç verse de istatistiksel öz-nitelik alt kümelerinin çoğunda DVM sınıflandırıcısı daha iyi sonuç vermiştir. Hatta bazı durumlarda $k$-en yakın komşu sinıflandırıcısı yüzde bazında 15 puan geride kalmıştır (MFKK-enerji), bu da DVM in bu problem türü için daha gürbüz ve istikrarlı sonuçlar verebildiğini ortaya koymaktadır.

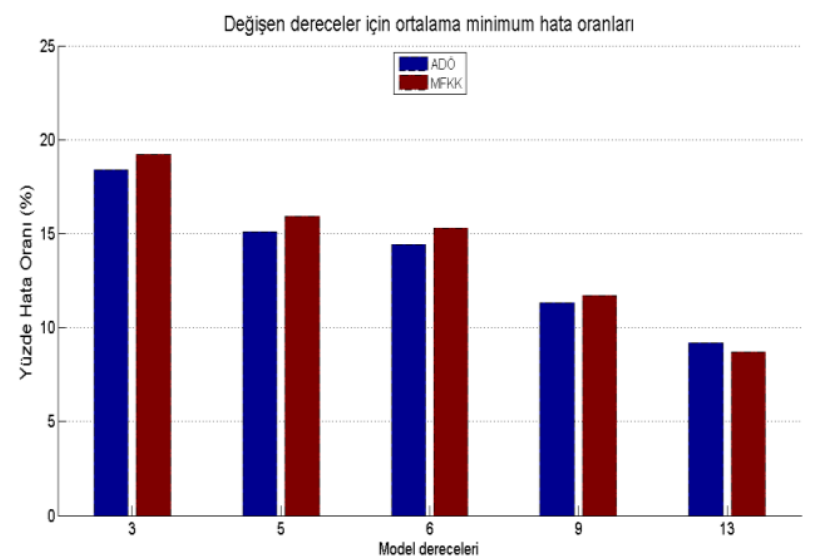

Şekil 3. MKKK ve ADÖ yöntemlerinin farklı model derecelerindeki en iyi ortalama hata oranları.

Tabloya tüm sonuçları koymak mümkün olmadığından, MFKK ve ADÖ yöntemlerinin başarılarının, kullanılan model derecesine göre nasıl değiştiğini açıklamak adına model derecesi 3 den 13 e doğru (literatürde rapor edilen dereceleri de içerecek şekilde) arttırılmış ve en düşük ortalama hata oranları Şekil 3'de verilmiştir. Model derecesi arttıkça hata oranlarının düştügü ve bir süre sonra anlamlı artışların olmadığı bulunmuştur. Bu sebeple en-iyi model derecesi olarak 13 seçilmiş ve analiz sonuçları verilmiştir.

\section{Tartışma ve Sonuç}

MFKK ve ADÖ gibi konuşma tanıma amacıyla önerilen sistemlerin solunum sesi problemi için de umut vadettiği görülmüştür. Bireysel sınıf bazında doğruluk için en iyi sonuçlar ADÖ yöntemi ile elde edilirken, tüm sınıfların ortalama doğruluk performansı MFKK yöntemi için daha yüksek çıkmıştır.

Literatürde, var olan güç spektrum yoğunluğu $[8,11]$ ve MFKK $[9,10]$ tabanlı yöntemler kendi veritabanlarında sadece ilgili yöntemi denemişlerdir, bu çalışmada ise hem daha önce tarafımızdan sağlıklı hastalıklı tanıma [15] amacıyla önerilen ADÖ yöntemi farklı bir problem olan üçlü sınıflandırmaya uygulanmıştır hem de literatürde üçlü sınıflandırma problemi üzerine önerilen yöntemlerle karşılaştırmalı sonuçlar elde edilmiştir. Ayrıca, ham öznitelikler veya öznitelik seçimi yerine en az sayıda istatistiksel öz-nitelik alt kümesi kullanılarak, [8] de olduğu gibi genetik algoritması tabanlı öznitelik seçimine ihtiyaç kalmadan daha yüksek başarıma ulaşılmıștır.

ADÖ oval, MFCC ise üçgen biçiminde süzgeçlere sahiptir, bu süzgeçlerin hangi alt öznitelik grubuna nasıl tepki verdiğinin (ayrımsayıcı bant geçiren süzgeç davranışı) işitsel modelleme alanında akıllı stetoskop tasarımında göz önünde bulundurulması faydalı olabilir.

DVM birkaç durumda $k$-en yakın komşu sinıflandırıcısının gerisinde kalsa da elde ettiği sonuçlar ortalamada hem daha iyi hem de daha kararlıdır. Fourier dönüşümü temelli oldukları için MFKK ve ADÖ zamansal çözünürlükleri (sabit zamanfrekans çözünürlüğü) ayrımsayıcı performansını bir noktaya kadar taşıyabilmektedir. Geleceğe yönelik olarak zamansal çözünürlüğü yüksek olan dalgacık dönüşümü temelli yöntemler daha yüksek başarım sağlayabilirler. Çıtırtı ve üfürümlerin zaman ve frekans alanında üst üste bindiği durumlar da gelecekte uğraşılması düşünülen problemlerdendir.

Tablo 1. Güç spektrum yoğunluğu (en üstte), Mel frekans kepstral katsayıları (ortada) ve algısal doğrusal öngörü (en altta) yöntemleri için k en yakın komşu ve destek vektör makineleri (DVM) doğruluk yüzdeleri

\begin{tabular}{|c|c|c|c|c|c|c|c|c|c|c|c|c|}
\hline \multirow{3}{*}{ Tip } & \multicolumn{12}{|c|}{ Öznitelik } \\
\hline & \multicolumn{2}{|c|}{ Enerji } & \multicolumn{2}{|c|}{ Entropi } & \multicolumn{2}{|c|}{ Standart sap. } & \multicolumn{2}{|c|}{ En küçülten } & \multicolumn{2}{|c|}{ En büyülten } & \multicolumn{2}{|c|}{ Basıklık } \\
\hline & $\begin{array}{c}K \text {-en } \\
\text { yakın }\end{array}$ & DVM & $\begin{array}{c}K \text {-en } \\
\text { yakın }\end{array}$ & DVM & $\begin{array}{c}K \text {-en } \\
\text { yakın }\end{array}$ & DVM & $\begin{array}{c}K \text {-en } \\
\text { yakın }\end{array}$ & DVM & $\begin{array}{c}K \text {-en } \\
\text { yakın }\end{array}$ & DVM & $\begin{array}{c}K \text {-en } \\
\text { yakın }\end{array}$ & DVM \\
\hline Çıtırtı & 86.0 & 90.5 & 48.5 & 51.5 & 60.0 & 72.5 & 68.5 & 76.0 & 81.0 & 82.0 & 67.5 & 71.0 \\
\hline Üfürüm & 46.5 & 76.0 & 39.0 & 48.7 & 49.0 & 67.0 & 42.0 & 39.5 & 61.0 & 73.0 & 63.5 & 47.0 \\
\hline Normal & 45.0 & 19.5 & 54.0 & 51.3 & 39.5 & 21.0 & 43.0 & 56.0 & 48.0 & 62.0 & 45.5 & 70.5 \\
\hline Ortalama & 59.2 & 62.0 & 47.2 & 50.5 & 49.5 & 53.5 & 51.2 & 57.2 & 63.3 & 72.3 & 58.8 & 62.8 \\
\hline Çıtırtı & 55.0 & 79.5 & 54.5 & 74.0 & 85.5 & 88.5 & 88.0 & 89.5 & 75.0 & 75.0 & 32.5 & 42.5 \\
\hline Üfürüm & 86.5 & 95.0 & 82.5 & 84.0 & 91.0 & 44.5 & 93.5 & 87.0 & 87.0 & 77.5 & 76.0 & 78.0 \\
\hline Normal & 81.5 & 92.5 & 54.0 & 47.0 & 40.5 & 87.5 & 92.5 & 92.5 & 87.0 & 87.5 & 57.5 & 68.5 \\
\hline Ortalama & 74.3 & 89.0 & 63.7 & 68.3 & 72.3 & 73.5 & 91.3 & 89.7 & 83.0 & 80 & 55.3 & 63.0 \\
\hline Çıtırtı & 90.5 & 94.0 & 50.5 & 53.5 & 84.5 & 89.5 & 75.5 & 92.5 & 71.5 & 87.0 & 53.0 & 59.5 \\
\hline Üfürüm & 90.0 & 79.0 & 46.5 & 41.0 & 95.5 & 72.0 & 92.0 & 86.0 & 91.0 & 87.5 & 79.0 & 81.0 \\
\hline Normal & 92.0 & 95.5 & 86.5 & 94.5 & 40.0 & 76.0 & 74.0 & 89.5 & 77.0 & 89.0 & 36.5 & 47.5 \\
\hline Ortalama & 90.8 & 89.5 & 61.2 & 63.0 & 73.3 & 79.2 & 80.5 & 89.3 & 79.8 & 87.8 & 56.2 & 62.7 \\
\hline
\end{tabular}




\section{Teşekkür}

Bu çalışma, Boğaziçi Üniversitesi Bilimsel Araştırma Projeleri Fonu tarafindan desteklenmiştir (Proje kodu:16A02D2). S. Ulukaya' nın çalışması Türkiye Bilimsel ve Teknolojik Araştırma Kurumu (TÜBİTAK) BİDEB 2211 programı çerçevesinde desteklenmiştir.

\section{Kaynakça}

[1] Gavriely, N., Cugell, D. W. 1995. Breath sounds methodology, CRC Press.

[2] Leng, S., Tan, R. S., Chai, K. T. C., Wang, C., Ghista, D., Zhong, L. 2015. The electronic stethoscope, Biomedical Engineering Online, 1-37.

[3] Oliveira, A., Marques, A. 2014. Respiratory sounds in healthy people: a systematic review, Respiratory medicine 108, 4(2014), 550-570.

[4] Reichert, S., Gass, R., Brandt, C., Andres, E. 2008. Analysis of respiratory sounds: state of the art, Clinical medicine. Circulatory, respiratory and pulmonary medicine, 2(2008), 45-58.

[5] Piirila, P., Sovijarvi, A. R. 1995. Crackles: recording, analysis and clinical significance, European Respiratory Journal, 8(1995), 21392148.

[6] Sankur, B., Güler, E. C., Kahya, Y. P. 1996. Multiresolution biological transient extraction applied to respiratory crackles, Computers in Biology and Medicine, 26(1996), 25-39.

[7] Meslier, N., Charbonneau, G., Racineux, J. L. 1995. Wheezes, European Respiratory Journal, 8(1995), 1942-1948.

[8] Güler, I., Polat, H., Ergün, U. 2005. Combining neural network and genetic algorithm for prediction of lung sounds, Journal of Medical Systems, 29(2005), 217-231.

[9] Matsunaga, S., Yamauchi, K., Yamashita, M., Miyahara, S. 2009. Classification between normal and abnormal respiratory sounds based on maximum likelihood approach. in: Acoustics, Speech and Signal Processing (ICASSP), IEEE International Conference on, 517-520.

[10] Mayorga, P., Druzgalski, C., Morelos, R. L., Gonzalez, O. H., Vidales, J. 2010. Acoustics based assessment of respiratory diseases using GMM classification, in: Engineering in Medicine and Biology Society (EMBC), 32nd Annual International Conference of the IEEE, 63126316.

[11] Abbas, A., Fahim, A.. 2010. An automated computerized auscultation and diagnostic system for pulmonary diseases, Journal of Medical Systems, 34(2010), 1149-1155.

[12] Hermansky, H. 1990. Perceptual linear predictive PLP analysis of speech, The Journal of the Acoustical Society of America, 87(1990), 1738-1752.

[13] Sen, I., Kahya, Y. P. 2005. A multi-channel device for respiratory sound data acquisition and transient detection, in: Engineering in Medicine and Biology Society (EMBC), 27th Annual International Conference of the IEEE, 66586661.

[14] Welch, P. D. 1967. The use of fast Fourier transform for the estimation of power spectra: A method based on time averaging over short, modified periodograms, IEEE Transactions on Audio and Electroacoustics 15, 2(1967), 70-73.

[15] Ulukaya, S., Kahya, Y. P. 2014. Respiratory sound classification using perceptual linear prediction features for healthy-pathological diagnosis. In 18th National Biomedical Engineering Meeting (BIYOMUT) 